\title{
REFRIGERATION TESTS OF THE CRYOGENIC SYSTEM AND SOLENOID \\ FOR THE FERMILAB COLLIDER DETECTOR*
}

R. W. Fast, K. Aihara, R. I. Dachniwskyj, R. D. Kephart, K. Kondo, H. Minemura, S. Mori, R. Saito, M. E. Stone, T. Suzuki, R. H. Wands and R. Yoshizaki

July 1984

*Presented at the 10th International Cryogenic Conference, Espoo, Finland, July 31-Aug. 3, 1984, and will be published by Butterworth Scientific, Ltd in the conference proceedings. 
REFRIGERATION TESTS OF THE CRYOGENIC SYSTEM AND SOLENOID FOR THE FERMILAB COLLIDER DETECTOR

R. W. Faşt, K. Aiharasa, ${ }^{*}$ R. I. Dachniwskyj, R, D. Kephart, K. Kondo, ${ }^{\dagger}$ H. Minęmura, ${ }^{\dagger}$ S. Mori, R. Saito, ${ }^{\dagger}$ M. E. Stone, T. Suzuki, ${ }^{\prime}$ R. H. Wands, and R. Yoshizaki

Fermi National Accelerator Laboratory, Batavia, Illinois**

* Hitachi, Ltd, Hi tachi, Ibaraki, Japan

$\dagger$ University of Tsukuba, Sakura, Ibaraki, Japan

A refrigeration system for the $3 \mathrm{~m} \phi \times 5 \mathrm{~m}$ superconducting solenoid for the Collider Detector at Fermilab has been installed and operated with a dummy load. The nominal 600-W capacity of the system was achieved in the initial test. The solenoid and integral control dewar was tested in Japan with a 300-W refrigerator. The cooldown time was 7 days and the measured heat load of $35 \mathrm{~W}$ agrees well with the estimated value.

\section{INTRODUCTION}

The Fermilab Collider will make possible experiments using proton-antiproton collisions at center of mass energies $\sim 2 \mathrm{TeV}$. The detector for these experiments will use a thin superconducting solenoid magnet $3 \mathrm{~m}$ in diameter, $5 \mathrm{~m}$ long, and $0.24 \mathrm{~m}$ in radial thickness. 1 The coil will be conduction cooled by forceed, twophase helium circulated through a cooling path. The coil has supports which are intercepted with liquid helium and liquid nitrogen. The refrigeration system and the solenoid were recently tested.

\section{REFRIGERATION REQUIREMENTS}

The helium temperature refrigeration requirement of the solenoid cryostat and control dewar was calculated to be $\sim 40 \mathrm{~W}$ plus $14 \mathrm{~L} / \mathrm{h}$ for the gas cooled leads. When the magnet is being charged to the design field of $1.5 \mathrm{~T}$ in 10 min there is an additional eddy current heat load of $\sim 100 \mathrm{~W}$. The transfer line, bayonets, u-tubes, and storage dewar contribute another heat load of $\sim 30 \mathrm{~W}$. The maximum total expected helium temperature refrigeration and liquefaction requirement is therefore $\sim 170 \mathrm{~W}+$ $14 \mathrm{~L} / \mathrm{h}$. The refrigeration system should be adequate to permit operation with an unexpectedly high heat leak, and to permit rapid cooldown of the magnet. The Collider will perform physics experiments continuously for a six-month period, after which the 2400-ton detector will be moved from the collision area to a large assembly hall approximately $30 \mathrm{~m}$ away. The cryosystem must allow detector operation in both of these positions. The solenoid is designed to quench safely; but the refrigeration system must be capable of withstanding the associated pressure rise and provide a rapid recovery to superconducting temperatures.

\section{REFRIGERATION SYSTEM DESCRIPTION}

The Fermilab satellite refrigerator was chosen as the basic component of the refrigeration system. ${ }^{2}$ The refrigerator consists of a 350-hp Mycom two-stage screw 
compressor and purifier, a four-stage counterflow heat exchanger with liquid nitrogen precooling, and two reciprocating expansion engines.

The refrigeration avallable from the system at the full compressor mass flow rate of $58 \mathrm{~g} / \mathrm{s}$ and with $14 \mathrm{~L} / \mathrm{h}$ withdrawn for the current leads is $\sim 550 \mathrm{~W}$, which is greater than the expected heat load during charge by a factor of 2.5. This additional refrigeration will permit rapid recovery from quenches and a cooldown to operating temperature in less than 4 days. The satellite was chosen primarily because the Fermilab Tevatron project has created a large body of experience in the operation and maintenance of the system. The collider satellite can be controlled from the main control room of the Tevatron, along with the 26 satellites which are necessary for the superconducting accelerator.

The flow diagram of the magnet refrigeration circuit is shown in Fig. 1. Refrigerator output is into a 2000-L storage dewar to provide the reservoir from which the magnet flow originates. Liquid helium flows through a transfer line into the control dewar subcooler where it is cooled by the magnet return flow. After leaving the subcooler the helium is expanded through a $J-T$ valve and flows into the magnet cooling circuit. This circuit is approximately $130 \mathrm{~m}$ of $20-\mathrm{mm}$ ID aluminum tubing welded to the outer support cylinder of the solenoid. Most of the cooling path is axially serpentine, with a circumferential loop at each end of the outer support cylinder. Another circumferential loop at each end intercepts the radial and axial supports.

The refrigerator control system is based on the Fermilab Tevatron system. ${ }^{1}$ Signals from pressure, temperature, engine speed, and other transducers are received by a Z-80 microprocessor in the multibus mainframe which performs the appropriate control functions. The multibus mainframe communicates through a CAMAC serial link with computers located near the accelerator main control room. These computers are connected to a control console near the refrigerator. Input and output variables, set points, operating limits for valves, and engine speeds can be changed from here or from other Tevatron consoles in a variety of locations.

An over-all view of the refrigeration system installed in the assembly hall is shown in Fịg. 2.

\section{TEST OF REFRIGERATOR}

The initial test of the refrigerator in March 1984 was to make liquid into the storage dewar. The refrigerator and dewar were cooled to liquid helium temperature in $\sim 12 \mathrm{~h}$. An electrical heater in the dewar was used to measure refrigeration and a superconducting-wi re liquid level gauge was used to obtain liquefaction rates. The level probe, temperatures (VPT and carbon resistors), pressures, and expander speeds were monitored with the control system. Valves were operated, their positions monitored, and the various feedback loops stabilized through the control system.

The speeds of both gas and liquid expanders were adjusted for maximum refrigeration output at each heater power setting. The result of this test is given in Fig. 3. The capacity appeared to be somewhat in excess of the nominal value for the satellite refrigerator.

\section{INITIAL TEST OF SOLENOID}

The inftial test of the solenold was performed at the Hitach Research Laboratorles in the spring of 1984, with the results of the electrical tests given elsewhere. ${ }^{3}$ A $300-W$ Hi tachi refrigerator was used for this test. It made liquid helium into a 2000-L storage dewar. A liquid helium pump contained in a separate valve box could be used to circulate helium through the magnet.

The Initial phase of the cooldown utilized only the refrigeration from the liquid nitrogen heat exchanger. The expansion turbine was turned on at a control 
dewar temperature $\sim 180 \mathrm{~K}$. The cooldown to the operating temperature of $4.7 \mathrm{~K} 1 \mathrm{~s}$ shown in Fig. 4; this took slightly more than seven days, an average cooldown rate of $1.7 \mathrm{~K} / \mathrm{h}$.

The refrigerator was operated in a steady state mode during the electrical tests. The pump was not used for these tests. The mass flow rate of helium through the magnet circuit was $17 \mathrm{~g} / \mathrm{s}$ with valve EVMC (Fig. 1) held completely open. The temperature and absolute pressure of the heliun leaving the subcooler were $\sim 4.7 \mathrm{~K}$ and $0.16 \mathrm{MPa}$.

The helium temperature heat load of the solenoid cryostat and control dewar was estimated from the steady state flow data using the pump. The heat load was also estimated from the time required to boil away the inventory in the cryostat and control dewar when the helium pump was turned off. These two methods gave consistent values which averaged to $\sim 35 \mathrm{~W}$. During warmup all sections of the coil went normal at about the same time, indicating an absence of local regions of high heat flux.

Throughout the test the liquid nitrogen cooled shields and intercepts operated between 92 and $97 \mathrm{~K}$ with a nitrogen supply temperature and absolute pressure of approximately $92 \mathrm{~K}$ and $0.45 \mathrm{MPa}$.

The relative humidity at Hitachi during the test was quite high (80-100\%). From the fact that condensation occurred on the vacuum shells at relative humidities above $85 \%$, it was estimated that the temperature of the vacuum vessel was below ambient by about $2 \mathrm{k}$.

\section{CONCLUSIONS}

Although the Fermilab refrigerator is larger than that used for the Hitachi test of the magnet, the operating performance of the magnet at Fermilab should be about the same. The cooldown data suggests that, with the larger Fermilab refrigerator, $\sim 6 \mathrm{~h}$ might be required to recover from a quench which results in a coil temperature of $100 \mathrm{~K}$.

The test program at Fermilab will investigate coil behavior, especially the thermal stability margin as a function of helium mass flow rate through the cooling circuit.

In summary, having accumulated test data on the Fermilab refrigeration system and the magnet separately, we are confident there will be no difficulty in combining them into a highly reliable system.

\section{REFERENCES}

(1) Wands, R. et a1. IEEE Trans in Magnetics 1983, MAG-19, 1368-1371

(2) Wands, R. H. and Fast, R. W. 'Advances in Cryogenic Engineering', Vo1. 29, 1984, P1enum, New York, p377-383

(3) Fast, R. W. et al. 'Fabrication and testing of a 3-m diameter superconducting solenoid for the Fermilab Collider Detector', Proc. 10th Int1 Cryo. Engr. Conf., Butterworth, Gulldford 

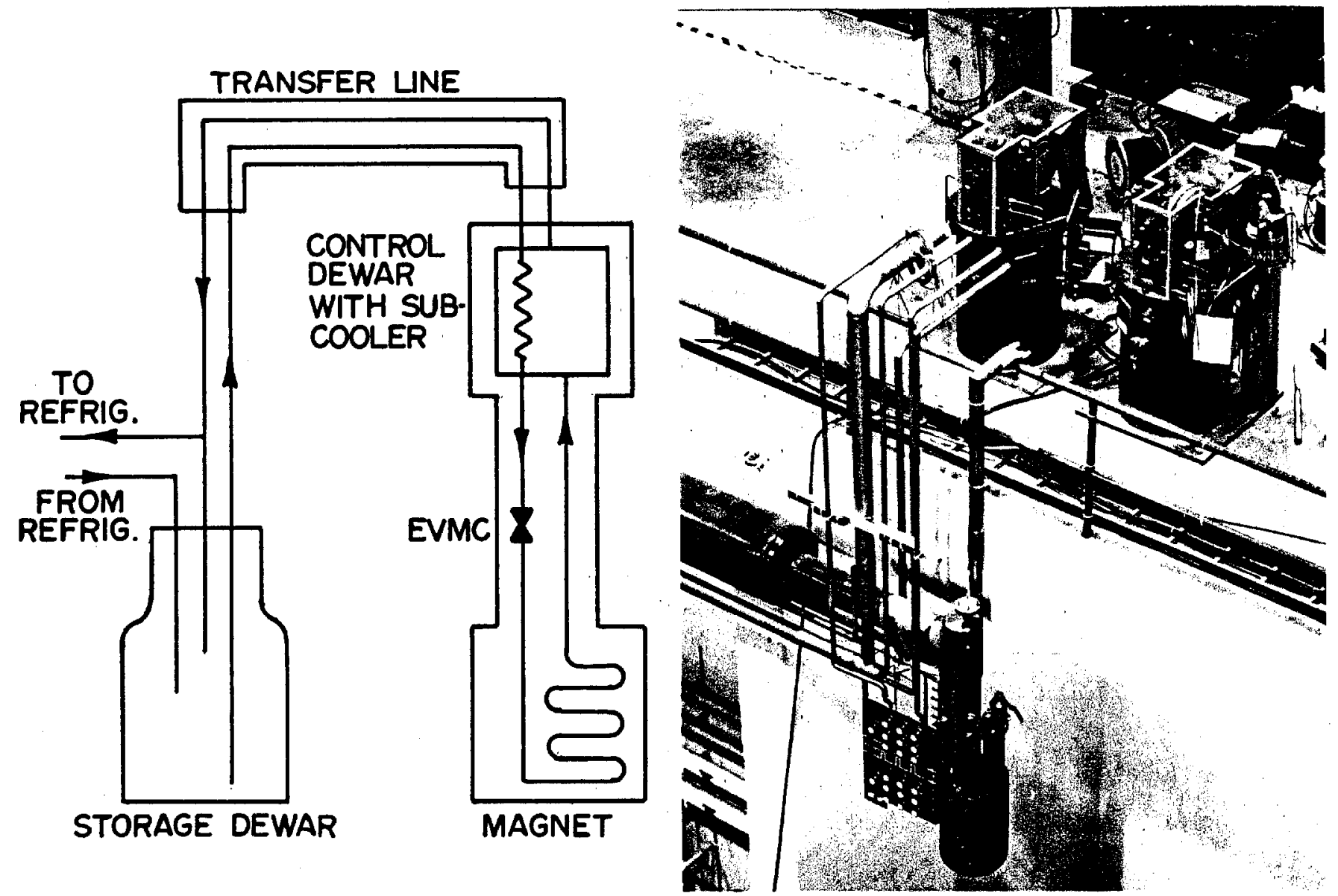

Fig. 1 Flow diagram of magnet refrigeration circuit

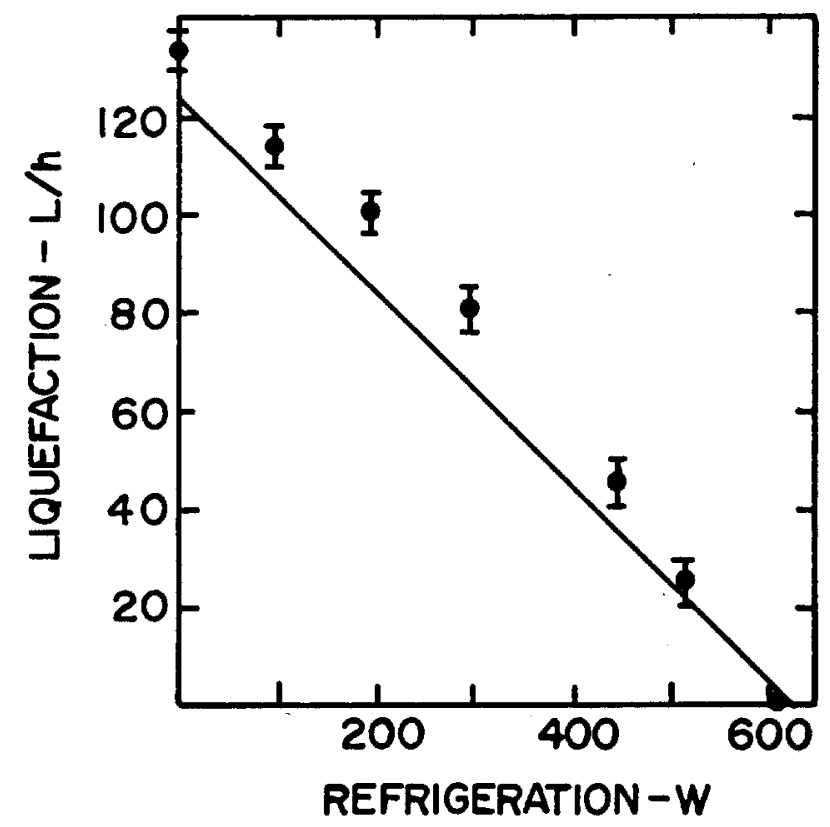

Fig. 3 Capacity of CDF refrigerator

Fig. 2 Refrigerator heat exchanger and expanders in CDF Assembly $\mathrm{Hall}$

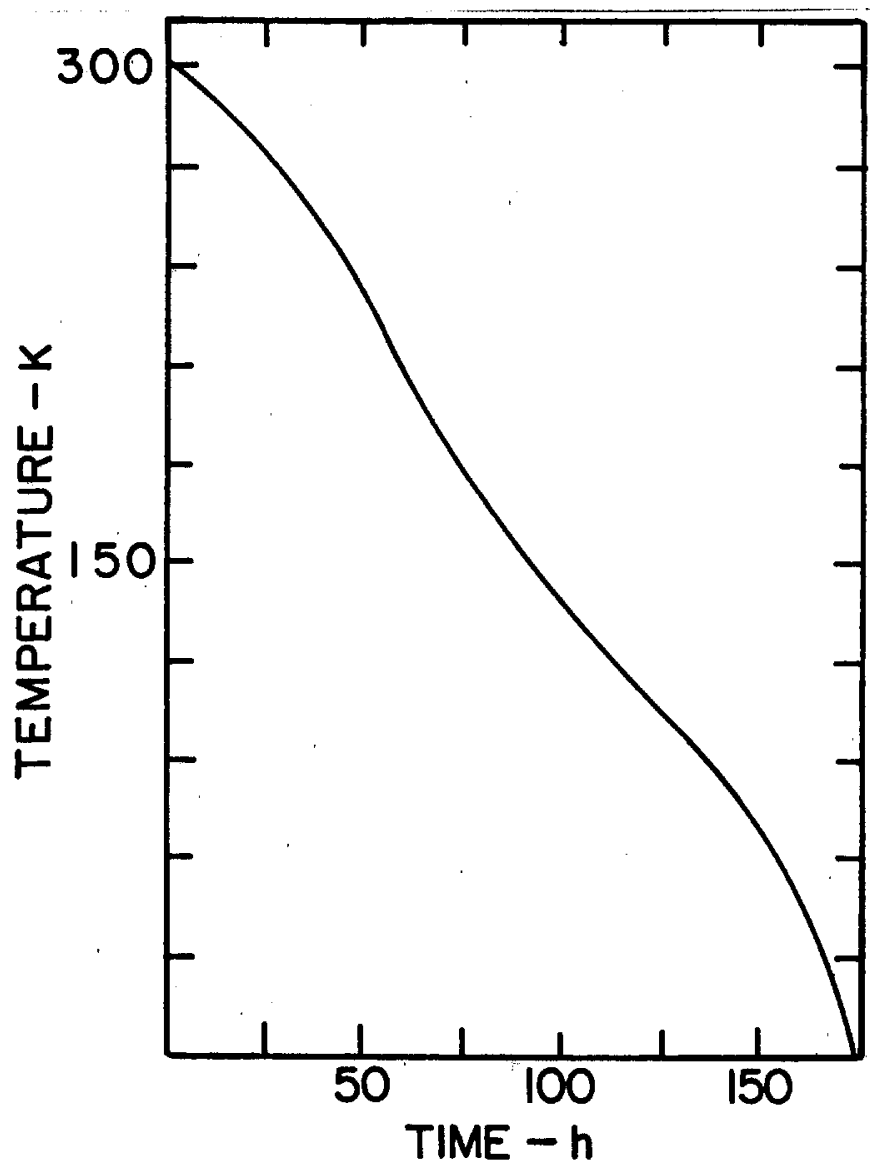

Fig. 4 Magnet cooldown - initial test at Hitachi 